\title{
ACERCA DEL CONCEPTO DE CORRUPCIÓN
}

Ernesto Garzón Valdés*

El sistema era así. Todos hemos pecado.

Bettino Craxi ${ }^{1}$

Yo pensaba que se trataba de un servicio normal y corriente. Pero me dijo que eran cinco millones de dólares. Monzer Al Kassar ${ }^{2}$

corrupción ha solido (y suele) ser enfocado desde dos perspectivas que dificultan su comprensión y condicionan su precisión conceptual. Una de ellas es la que podría ser llamada la "perspectiva de la modernización": la corrupción sería un fenómeno propio de regímenes políticos no evolucionados, es decir, que cuanto mayor sea el grado de desarrollo o de modernización de una sociedad política, tanto menor

* Universidad de Maguncia.

${ }^{1}$ Declaración de Bettino Craxi a propósito de las acusaciones de corrupción, citada según Die Zeit del 30.12.1994.

${ }^{2}$ Declaraciones de Al Kassar acusando al juez español Baltasar Garzón de extorsión. Cfr. El País del 10.1.1995, p. 16.

0. $\mathrm{E}_{1 \text { estudio del fenómeno de la }}$ 


\section{ERNESTO GARZÓN VALDÉS}

habrá de ser el grado de corrupción. ${ }^{3}$ Max Weber había ya sostenido la tesis según la cual

El dominio universal de la absoluta inescrupulosidad en la búsqueda de intereses egoístas para hacer dinero ha sido precisamente un rasgo muy específico de aquellos países cuyo desarrollo capitalista burgués ha permanecido rezagado de acuerdo con las pautas del desarrollo occidental. ${ }^{4}$

Medio siglo más tarde Colin Leys relativizaba esta tesis: la corrupción no sería un "rasgo específico" de los países en desarrollo, pero en ellos existiría una mayor probabilidad de que se produjesen actos o actividades corruptos(as):

Es claro que muy probablemente los nuevos Estados serán el escenario de muchos comportamientos que pueden ser llamados corruptos. [...] Es relativamente fácil encubrir la corrupción en los nuevos Estados. Esto se debe, parcialmente, al hecho de que la gente no sabe con claridad cuáles son las reglas oficiales o qué es realmente) lo que constituye su violación; o si lo saben claramente, puede ser que no les importe mucho su violación y que no tengan mucho interés en prevenir la corrupción. ${ }^{5}$

${ }^{3}$ Cfr., por ejemplo, Amitai Etzioni, Capital Corruption: The New Attack on American Democracy, 1984, San Diego, Harcourt.

${ }^{4}$ Cfr. Max Weber, Die protestantische Ethík, 1979, Gütersloh, Gerd Mohn, p. 47.

${ }^{5}$ Cfr. Colin Leys, "What is the problem about corruption?" en Arnold J. Heidenheimer, Michael Johnson y Victor T. LeVine, Political Corruption A Handbook, 1993, New Brunswick/Londres, Transaction Publishers, p. $51-66$ y 59. 
La realidad cotidiana de los países altamente industrializados ha puesto de manifiesto la falsedad de esta tesis. ${ }^{6}$

La segunda perspectiva es la "perspectiva de la moralidad". A diferencia de la primera, ella es parcialmente verdadera pero tiende o bien a establecer una relación empíricamente dudosa entre coacción y corrupción o bien a considerar que todos los casos de corrupción son moralmente reprochables.

Como ejemplo de la primera alternativa, valga la afirmación de Carl J. Friedrich:

Es posible constatar una 'regularidad' o una regla general. Y puede decirse que el grado de corrupción varía inversamente con el grado en que el poder es consensuado. [...] en aquellas situaciones en donde una apariencia de consenso oculta la realidad coercitiva, hay que contar con la corrupción. El poder del que se supone que es ejercido con el consentimiento de los gobernados pero que se ha transformado en coacción en grado considerable, conduce a la corrupción. ${ }^{7}$

Esta supuesta correlación entre mayor democracia y menor corrupción o, lo que es lo mismo, entre dictadura y corrupción no es empíricamente sostenible. Es significativo que haya habido menos corrup-

${ }^{6}$ Como fuente informativa del grado de corrupción en la República Federal de Alemania, pueden consultarse, entre otros, Rolf Ebbighausen y Sighard Neckel, Anatomie des politischen Skandals, 1989, Francfort del Meno, Suhrkamp; Hans Herbert von Arnim, Der Staat als Beute - Wie Politiker in eigener Sache Gesetze machen, 1993, Münich, Th. Knaur Nachf; Erwin y Ute Scheuch, Cliquen, Klügel und Karrieren, 1992, Hamburgo, Rowohlt; y Georg M. Hafner y Edmund Jacoby (eds.), Neue Skandale der Republik, 1994, Reinbeck/Hamburgo, Rowohlt.

${ }^{7}$ Cfr. Carl J. Friedrich, Pathologie dex, Politik. Die Funktion der Missstände: Gewalt, Verrat, Corruption, Geheimhaltung, Propaganda, 1973, Francfort/Nueva York, Herder \& Herder, p. 104 s. 


\section{ERNESTO GARZÓN VALDÉS}

ción bajo Stalin que bajo los regímenes soviéticos o rusos subsiguientes $^{8}$ y que las democracias occidentales abunden en ejemplos de corrupción gubernamental.

La siguiente cita de John T. Noonan, Jr. puede ilustrar la segunda alternativa:

El soborno es una vergüenza universal. No hay un país en el mundo que no considere al soborno como un delito en sus textos jurídicos. Existen algunas leyes, como las que tratan del juego, que son violadas constantemente sin ninguna sensación especial de vergüenza afín al delito. La ley sobre el soborno no está entre ellas. [...] La vergüenza y la hipocresía en el uso del lenguaje son el tributo del vicio a la virtud. La vergüenza puede ser condicionada culturalmente. La vergüenza tan intensa y tan general es el reconocimiento de que hay algo objetable en la conducta que va más allá de lo descortés y puramente legal. La vergüenza no la establece en forma concluyente, pero sí señala la naturaleza moral de la cuestión."

182 La perspectiva de la moralidad impide ver la diferencia que puede existir entre la violación de un sistema normativo positivo y la del sistema de una moral con pretensiones de universalidad como la que parece sustentar Noonan. No alcanzo a comprender cuál pudiera ser la "vergüenza" que pueda haber sentido Oskar Schindler al sobornar a los jefes de un campo de concentración nazi y salvar así la vida de no pocos prisioneros judíos.

${ }^{8}$ Cfr. sobre éste y otros ejemplos similares, Jon Elster, The Cement of Society. A study of social order, 1989, Cambridge, Cambridge University Press, p. 265.

${ }^{9}$ Cfr. John T. Noonan, Jr., Bribes, 1984, Nueva York, Macmillan, p. 702 s., citado según Robert Klitgaard, Controlando la corrupción. Una indagación práctica para el gran problema social de fin de siglo, 1988, Buenos Aires, Sudamericana, p. 26. 


\section{EL CONCEPTO DE CORRUPCIÓN}

En lo que sigue, habré de prescindir totalmente de la perspectiva de la modernización y, al menos inicialmente, de la de la moralidad.

1. El concepto de corrupción está lógicamente vinculado con el de sistema normativo. No es posible hablar de corrupción sin hacer referencia simultáneamente al marco normativo dentro del cual se produce el acto o la actividad calificada de corrupta. Llamaré al sistema normativo con respecto al cual un acto o una actividad es calificadora de corruptora "sistema normativo relevante".

2. Para los fines del presente trabajo, entenderé por sistema normativo relevante todo conjunto de reglas que -en dado caso concreto- regulan una práctica social. En este sentido, puede hablarse, por ejemplo, de sistemas normativos religiosos, jurídicos, políticos, económicos, deportivos, etc. Esto significa rechazar la concepción habitual según la cual el fenómeno de la corrupción es eminentemente político. No hay inconveniente semántico alguno en hablar de deportistas, de directores de empresas o de sacerdotes corruptos en el mismo sentido en que puede hablarse de gobernantes o diputados corruptos. Significa abandonar también la idea de que para hablar de corrupción hay que hacer necesariamente referencia a una persona que ocupa una posición oficial, es decir, a una autoridad o, lo que es lo mismo, a alguien que detenta un poder.

3. Sin embargo, sería falso inferir de aquí la conclusión de que la insistencia tradicional en la necesidad de la participación de una autoridad en los actos o actividades de corrupción no contiene referencias indirectas interesantes. Ellas son, por lo menos, las dos siguientes. Por lo pronto, alguien es una autoridad cuando, entre otras cosas, tiene competencia para tomar decisiones; es, por ello, un decisor. Pero, el carácter de decisor no tiene por qué estar limitado a una autoridad. Alguien puede ser un decisor en virtud del papel social que desempeña o de la posición que ocupa dentro del sistema normativo relevante, sin que ello implique necesariamente la potestad para-dictar disposiciones jurídicamente obligatorias. En los actos o actividades de corrupción interviene siempre, por lo menos, un decisor. 


\section{ERNESTO GARZÓN VALDÉS}

Pero, además, segundo, los cargos oficiales imponen a quienes los detentan una serie de deberes. Este tipo de deberes específicos suelen ser llamados "institucionales". El decisor que interesa para la consideración del fenómeno de la corrupción está sujeto a este tipo de deberes. En general, y sobre todo para los casos en los que los sistemas normativos relevantes no son políticos o jurídicos, la expresión "deberes institucionales" puede ser sustituida sin mayor inconveniente por la de "deberes posicionales". Es posible, en este sentido, hablar de los derechos y deberes institucionales o posicionales de un gobernante, de un juez, de un futbolista, de un sacerdote o de un director de empresa.

4. Los deberes posicionales ${ }^{10}$ deben ser distinguidos de los llamados deberes naturales. Éstos valen para todos y con respecto a todos los individuos, sin que importe el papel social que ellos desempeñen. De estos deberes se ocupa la "moral natural". En cambio, aquéllos se adquieren a través de algún acto voluntario en virtud del cual alguien acepta asumir un papel dentro de un sistema normativo; su ámbito de validez está delimitado por las reglas que definen la posición respectiva. La moral que se ocupa de los deberes posicionales suele ser llamada "moral adquirida". 11

184 En este contexto, hay también otra distinción que es útil tomar en cuenta si se acepta la relevancia de los deberes posicionales. Es la bien conocida entre deber y obligación. El deber caería dentro del ámbito de la moral natural y sería equivalente a deber natural. La obligación, en cambio, correspondería al ámbito de la moral adquirida y sería el equivalente a deber posicional. Por ello, puede decir John Rawls:

${ }^{10}$ Con respecto al concepto de deber posicional, cfr., por ejemplo, Michael Philips, "Bribery", en Ethics, vol. 94, julio 1984, p. 621-36 y 622.

${ }^{11}$ Cfr. Benjamin Freedman, "What Really Makes Professional Morality Different: Response to Martin", en Ethics, vol. 91, n 4, 1981, p. 626-30, aquí 627. 
También quien asume un cargo público está obligado con respecto a sus conciudadanos cuya confianza ha buscado y con quienes coopera en la gestión de una sociedad democrática. De manera similar, asumimos obligaciones cuando nos casamos y cuando aceptamos posiciones en la Justicia, en la administración o alguna otra autoridad. Adquirimos obligaciones a través de promesas y acuerdos tácitos y cuando participamos en un juego, es decir, la obligación de jugar de acuerdo con las reglas y ser un buen deportista. ${ }^{12}$

La corrupción es un delito o una infracción que implica la violación de alguna obligación por parte de un decisor. Por ello, no tiene sentido decir, por ejemplo, que se corrompe a un criminal para que mate a alguien y viole así el deber natural de no matar. Se puede, en cambio, corromper a un arquero de un equipo de fútbol para que no cumpla su obligación de defender el arco, ${ }^{13}$ a un juez para que viole su obligación de fallar imparcialmente y al guardián de un campo de concentración para que no cumpla las instrucciones de sus jefes.

Si se acepta que las obligaciones son deberes adquiridos por promesas o aceptación expresa o tácita de una determinada posición en una práctica social, no cuesta admitir que la corrupción implica siempre un acto de deslealtad o hasta de traición con respecto al sistema normativo relevante. ${ }^{14} \mathrm{El}$ que esta deslealtad sea también éticamente repro-

${ }^{12}$ Cfr. John Rawls, A Theory of Justice, 1972, Oxford, Clarendon Press, p. 113.

${ }^{13}$ Tal parece haber sido el caso de Bruce Grobbelaar, arquero del Liverpool, quien habría recibido 40.000 libras de una organización asiática a cambio de amañar un partido de la Liga inglesa el 21 de noviembre de 1993 en el que su equipo perdió por 3:0 frente al Newcastle. Cfr. El País del 10.11.1994, p. 55. En el Mundial sub 20, disputado en Qatar en abril de 1995, la delegación chilena denunció a la FIFA intentos de soborno por parte de ciudadanos asiáticos (cfr. El País del 22.4.1995, p. 41).

${ }^{14}$ Con respecto a la vinculación entre corrupción y traición cfr. Carl J. Friedrich, op. cit., p. 114. 


\section{ERNESTO GARZÓN VALDÉS}

chable es algo que no es posible predicar con independencia de la calidad ética del sistema normativo relevante. Esta calidad no puede ser conferida por el sistema mismo sino sólo tomando en cuenta los principios y reglas de un sistema moral crítico o ética. Para distinguirlo del sistema normativo relevante, llamaré a este sistema "sistema normativo justificante o excusante". Sobre esto volveré más adelante.

5. El acto o actividad corruptora requiere, a más del decisor, la intervención de una o más personas, decisoras o no. ${ }^{15}$ Es un delito o infracción participativo en el que una de las partes intenta influenciar el comportamiento de la otra a través de promesas, amenazas o prestaciones prohibidas por el sistema normativo relevante.

6. El objetivo que persigue este tipo de influencia es la obtención de un beneficio o una ganancia para las partes que participan en el acto o actividad corruptora. La corrupción es siempre una fuente adicional de ingresos o beneficios para quienes participan en ella.

En el caso del agente corrupto, estos beneficios son casi siempre de índole económica, pero no queda excluida la posibilidad de que ellos consistan en otro tipo de gratificaciones no directamente evaluables en dinero. Basta pensar en el otorgamiento de honores, premios u otro

186 tipo de favores no obtenibles a través del cumplimiento de un deber posicional. Llamaré a este tipo de ganancias "beneficios extraposicionales".

En el caso de quien corrompe o es destinatario del acto o actividad corrupto(a), el beneficio puede ser también económico o no y hasta consistir en la obtención de algo para lo que tiene derecho de acuerdo con el sistema normativo relevante pero que, debido a la violación de una obligación por parte del decisor, es sólo obtenible a través de un acto o actividad corruptora.

Los beneficios extraposicionales proceden o bien del agente que corrompe al decisor o de la persona destinataria del acto o la actividad

${ }^{15}$ Para casos de corrupción en los que ambas partes son decisores, $\mathrm{cfr}$. Hans Herbert von Arnim, Staat ohne Diener - Was schert die Politiker das Wohl des Volkes?, 1993, Múnich, Kindler, p. 171 s. 


\section{EL CONCEPTO DE CORRUPCIÓN}

corrupto(a). Tomando en cuenta el origen de los beneficios extraposicionales, es posible distinguir dos tipos fundamentales de corrupción: el soborno y la extorsión:

Se soborna a un decisor cuando se le otorga un beneficio extraposicional para que viole su obligación y se es extorsionado cuando se otorga a un decisor un beneficio extraposicional para que cumpla su obligación.

El cumplimiento de una obligación suele admitir diversos matices. Así, por ejemplo, una obligación puede ser satisfecha rápidamente, con entusiasmo y eficacia o cumplida con desgano, rutinaria y lentamente hasta un punto tal que la actitud del decisor puede ser interpretada como una tendencia a no cumplir su obligación. En este último caso, el ofrecimiento de dinero u otro tipo de beneficios para asegurar un más rápido cumplimiento de la obligación no suele ser considerado como soborno sino más bien como señal de una velada extorsión. Decisores que requieren un estímulo extra para el cumplimiento adecuado de sus obligaciones son, por así decirlo, "extorsionadores encubiertos". Es significativo que, por ejemplo, la Foreign Corrupt Practices Act (FCPA) de los Estados Unidos no considere estos casos como ejemplos de corrupción-soborno. Thomas L. Carson ${ }^{16}$ sugiere que estos pagos son una especie de "propina" similar a la que se paga a un camarero en un restaurante. La diferencia estaría en que la propina se entrega voluntariamente después de realizado el servicio (y la forma cómo se haya realizado condiciona también el monto de la propina que adquiere, en algunos casos, la categoría de premio y en otros, de castigo) mientras que en el caso de los pagos para engrase de la máquina burocrática, de los grease payments, el dinero es entregado por adelantado y semi voluntariamente. Por ello, como observa el propio Carson,

${ }^{16}$ Cfr. Thomas L. Carson, "Bribery, Extorsion, and 'The Foreign Corrupt Practices Act'", en Philosophy \& Public Affairs, 1985, vol. 14, n 1, p. 66-90. 
ERNESTO GARZÓN VALDÉS

suele haber aquí una pendiente resbaladiza que fácilmente conduce a la extorsión. ${ }^{17}$

7. Tomando en cuenta lo hasta aquí expuesto, puede proponerse la siguiente definición de corrupción:

$\mathrm{D}_{1}$

La corrupción consiste en la violación de una obligación por parte de un decisor con el objeto de obtener un beneficio personal extraposicional de la persona que lo soborna o a quien extorsiona.

8. Pero también el sobornante y el extorsionado obtienen un beneficio. El sobornante lo hace para obtener un bien personal sólo obtenible a través de la violación de una obligación del decisor; el extorsionado satisface los requerimientos del extorsionante para evitar un mal y obtener así el bien que le correspondería si el agente no violase su obligación. Pero, tanto el sobornante como el extorsionado prefiere aportar una prestación extra a no obtener el bien en cuestión. Es decir:

$\mathrm{D}_{2}$

La corrupción consiste en la violación de una obligación por parte de un decisor con el objeto de obtener un beneficio personal extraposicional de la persona que lo soborna o a quien extorsiona, a cambio del otorgamiento de beneficios para el sobornante o el extorsionado, que superan los costos del soborno o del pago o servicio extorsionado.

9. Si se admite que la corrupción es fuente de beneficios para los participantes y, además, que querer obtener beneficios que superen los costos de su obtención suele ser expresión de comportamiento racional, puede aceptarse la siguiente consideración de Stephen D. Morris:

${ }^{17}$ Ibidem, p. 80. 


\section{EL CONCEPTO DE CORRUPCIÓN}

La corrupción es un acto racional y, por consiguiente, promueve los intereses privados de sus participantes. Esto vale tanto para el soborno como para la extorsión, aunque hay alguna diferencia. Sin embargo, la extorsión se diferencia del soborno en el hecho de que la relación es de alguna manera más asimétrica, con mayores beneficios acumulados para el funcionario porque la sanción positiva ofrecida en un soborno representa un costo para el ciudadano mientras que la sanción negativa utilizada en el caso de la extorsión (abuso de autoridad) no constituye una pérdida para el funcionario sino que puede ser utilizada nuevamente dentro de ciertos límites. ${ }^{18}$

10. Dado que la ganancia que el corrupto obtiene es extraposicional, es decir, es una ganancia externa a la actividad misma, ${ }^{19}$ no cuesta mucho inferir que el carácter externo de esta ganancia, por lo general provoca en el decisor un conflicto de motivaciones e intereses con respecto a la actividad o práctica de que se trata: por un lado, el corrupto suele desear conservar su posición en el sistema, ya que es ella la que le permite obtener tanto la remuneración regular como la ganancia adicional: es "una fuente de ventaja discreta y selectiva". ${ }^{20}$ Por otro, como la ganancia adicional o externa sólo puede obtenerla violando sus obligaciones, es decir, socavando las bases de su propia posición, el acto o la actividad corrupto(a) tiene siempre un efecto corrosivo con respecto al sistema normativo relevante. Es una "opción

${ }^{18} \mathrm{Cfr}$. Stephen D. Morris, Corruption \& Politics in Contemporary Mexico, 1991, Tuscaloosa/Londres, The University of Alabama Press, p. 8 s.

${ }^{19}$ Sobre el concepto de pay-off externo a la actividad que uno realiza regularmente, Cfr. John McMurtry, "How Competition goes Wrong", en Journal of Applied Philosophy, 1991, vol. 8, $\mathrm{n}^{\circ}$ 2, p. 201-9, especialmente $204 \mathrm{~s}$.

${ }^{20} \mathrm{Cfr}$. Jeanne Becquart-Leclercq, "Paradoxes of Political Corruption. A French View", en Arnold J. Heidenheimer et al., Political Corruption, op. cit., p. 191-210 y 195. 


\section{ERNESTO GARZÓN VALDÉS}

destructiva". ${ }^{21}$ El corrupto, si quiere conservar el carácter racional de su actividad, tiene pues que practicar un juego doble con objetivos recíprocamente opuestos: el de la conservación del sistema normativo relevante y el de la obtención de los beneficios extraposicionales, violando este mismo sistema. ${ }^{22}$

Dicho con otras palabras: el problema práctico con el que se ve enfrentado el corrupto es el de cómo conciliar la existencia simultánea del sistema normativo relevante y del subsistema de corrupción que tan provechoso le resulta. La forma más eficaz de lograr este objetivo consta de dos pasos a diferentes niveles:

a) Adhesión retórica al sistema normativo relevante. Éste pasa a jugar un papel casi metafísico, mítico. Es lo que BecquartLeclercq llama "dimensión simbólica":

Además de ideologías, esta dimensión incluye el propósito de las leyes en la medida en que es definido por el legislador, independientemente de su aplicación práctica. ${ }^{23}$

Los latinoamericanos solemos ser expertos en el cultivo de la dimensión simbólica de las leyes. Con respecto al caso de México, Pablo González Casanova se ha referido en páginas memorables a este "mecanismo simbólico", "tradicional y metafísico" que desplaza a la Constitución y las leyes a la esfera del mito político. ${ }^{24}$

${ }^{21}$ Cfr. John McMurtry, op. cit.

${ }^{22}$ Como un caso posible, aunque excepcional, podría pensarse en la situación en la que el beneficio extraposicional que se busca es justamente el derrumbe del sistema.

${ }^{23}$ Cfr. Becquart-Leclercq, op. cit., p. 202.

${ }^{24}$ Cfr. Pablo González Casanova, La democracia en México, 1965, México, Era, sobre todo p. $32 \mathrm{~s}$. 
La adhesión retórica al sistema normativo relevante es la negación de lo que H. L. A. Hart llama "punto de vista interno", es decir, la aceptación del sistema en el sentido fuerte de ver en él la justificación última de las obligaciones de todo decisor. Si, siguiendo también a Hart, se admite que el punto de vista interno de los decisores es condición necesaria para la estabilidad y hasta la existencia de un sistema normativo, no cuesta inferir que el acto o la actividad corrupto(a) es directamente antisistémico, es decir, es siempre disfuncional para el sistema normativo relevante.

b) Creación de una red de complicidad basada en el acuerdo expreso o tácito entre el que soborna y el sobornado o el que extorsiona y el que es extorsionado. Esta complicidad crea lazos de cooperación entre los beneficiarios del subsistema de la corrupción. Esta sería la "dimensión operacional o estratégica". 25

Los beneficiarios del subsistema corrupción constituyen grupos que caen dentro de la categoría de aquellas asociaciones que Reinhard Zintl llama "camarillas":

Las camarillas son una determinada especie de coaliciones de distribución que juegan el juego de la distribución allí donde las reglas no lo prevén es decir, juegan el juego de la distribución con medios no permitidos. ${ }^{26}$

La creación de camarillas es notoria en el caso del soborno, en donde el sobornante espera un tratamiento preferencial de sus deseos e intereses y establece una relación de complicidad con el sobornado. De esta manera, se produce una distorsión de

${ }^{25}$ Cfr. Becquart-Leclercq, op. cit., loc. cit.

${ }^{26} \mathrm{Cfr}$. Reinhard Zintl, "Clubs, Clans und Cliquen", en Bend-Thomas Ramb y Mandred Tiezel, Ökonomische Verhaltenstheorie, 1993, Mứnich, Franz Vahlen, p. 89-117 y 108. 


\section{ERNESTO GARZÓN VALDÉS}

los criterios de decisión impuestos por el sistema normativo relevante sobre la base de relaciones de reciprocidad excluyentes. Por ello, el pago de soborno

[...] distorsiona inequitativamente las decisiones oficiales. ${ }^{27}$

En el caso de la extorsión, la camarilla suele surgir entre los extorsionadores, que no sólo se encubren recíprocamente sino que también acostumbran a distribuirse colegialmente entre sí los beneficios extorsionados. ${ }^{28}$

11. Mientras que la dimensión retórica está caracterizada por un discurso público de adhesión formal a las normas del sistema, la dimensión estratégica procura el silencio y el disimulo y trata que el número de miembros del subsistema de la corrupción no aumente disfuncionalmente.

Es por ello acertada la observación de Jon Elster:

Aun cuando todos sepan que existen prácticas corruptas, la necesidad de mantenerlas en secreto impone un límite a su extensión. $^{29}$

${ }^{27} \mathrm{Cfr}$. James Lindgren, "The elusive distinction between bribery and extortion. From the Common Law to the Hobbs Act", en UCLA Law Review, vol. 35,1988 , p. $815-909$ y 824.

${ }^{28}$ Tal es el caso, por ejemplo, de la policía mexicana: los patrulleros que extorsionan a los automovilistas, exigiendo pagos por la exención de multas a raíz de infracciones de tráfico no cometidas, entregan un porcentaje de la sumas cobradas a los respectivos comisarios quienes a su vez transfieren parte de estas ganancias a sus superiores inmediatos y así sucesivamente. ${ }^{29}$ Cfr. Jon Elster, The cement of society. A study of social order, 1989, Cambridge, Cambridge University Press, p. 271. 


\section{EL CONCEPTO DE CORRUPCIÓN}

12. El abandono del punto de vista interno con respecto al sistema normativo relevante y la creación de camarillas constituyen conjuntamente las bases de un subsistema que tiende a expandirse hasta rozar los límites de la eliminación total del sistema normativo relevante. Por ello, la corrupción-soborno tiene una pretensión normativa antisistémica que la coloca en la vecindad de las actividades revolucionarias. Al igual que estas últimas, conduce a la destrucción "del sistema de creencias que constituye el fundamento de un determinado sistema político". ${ }^{30}$ En este sentido, podría pensarse en la posibilidad de agentes revolucionarios que recurrieran al soborno, por ejemplo, para corromper a los decisores, alterar así totalmente las reglas de imposición de cargas y beneficios en una sociedad y provocar el derrumbe del sistema.

La diferencia fundamental entre el acto revolucionario y la corrupción consiste en que mientras el revolucionario desea el derrocamiento del sistema normativo relevante y puede recurrir a la corrupción como medio, el corrupto persigue un doble objetivo realizable sólo si se conserva el sistema.

Por ello, si bien es verdad que la corrupción se autoalimenta, reproduce por sí misma, también lo es que un exceso de glotonería o de actividad reproductora es, por definición, suicida para la corrupción. Así como no pueden existir mentirosos sin un entorno de personas veraces o gorrones en un grupo social en donde todos lo son, una sociedad en la que todos son corruptos es una contradicción in terminis:

[...] si todos pueden ser comprados, no es muy claro qué es lo que uno está comprando. ${ }^{31}$

Por ello es que hablar de un sistema totalmente corrupto en el que todos pecan, como afirma Craxi, es sólo posible si se juzga al sistema desde afuera, es decir, desde un sistema normativo evaluador que ca-

${ }^{30}$ Cfr. Carl J. Friedrich, op. cit., p. 105.

${ }^{31}$ Cfr. Jon Elster, op. cit., p. 265. 


\section{ERNESTO GARZÓN VALDÉS}

lifica negativamente las prácticas de un sistema al que se coloca la etiqueta de corrupto por referencia a este metasistema.

El soborno generalizado se convierte en una especie de sobresueldo o sobregratificacíón del decisor y la extorsión sistemática en una suerte de sobretasa que hay que pagar por un servicio inicialmente gratuito o menos costoso. Sólo cuando se produce un aumento súbito o excepcional de la remuneración podría entonces hablarse de soborno o extorsión. Esto es posiblemente lo que pensó el "financista y hombre de negocios" Al Kassar al afirmar que un "servicio normal y corriente" de un juez (que en la concepción al kassariana consistiría en que un decisor judicial otorga favores previo pago extra) se había vuelto demasiado caro.

13. Si se tienen en cuenta estas consideraciones, puede decirse:

$\mathrm{D}_{3}$

La corrupción consiste en la violación limitada de una obligación por parte de uno o más decisores con el objeto de obtener un beneficio personal extraposicional del agente que lo(s) soborna o a quien extorsiona(n) a cambio del otorgamiento de beneficios para el sobornante o el extorsionado que superan los costos del soborno o del pago o servicio extorsionado.

14. Dado que en el caso del soborno a lo que se aspira es a influenciar el comportamiento del sobornado, es decir, a que la expectativa de un beneficio sólo obtenible a través del acto o la actividad corrupto(a) sea lo que motive su decisión, el éxito de esta influencia depende de cuál sea la motivación real del comportamiento del sobornado. Pudiera ser el caso, por ejemplo, que el sobornado hubiera actuado de la misma manera a como actuó aun en el caso en que no se le hubieran otorgado estos beneficios extraposicionales. Como es sabido, éste es el argumento que utilizó Francis Bacon cuando en 1621 fue acusado de corrupción: 


\section{EL CONCEPTO DE CORRUPCIÓN}

Cuando pronunciaba una sentencia o daba una orden, no tenía en mente un soborno o una recompensa. ${ }^{32}$

Desde luego, dada la dificultad empírica de determinar en cada caso cuál fue la verdadera motivación del decisor y la tendencia humana generalizada a reaccionar favorablemente ante el ofrecimiento de beneficios suplementarios, cuando la decisión coincide con los deseos de quien los ofrece existe una presunción fuerte en el sentido de que el soborno fue la motivación decisiva. Posiblemente esto fue también lo que pensó Bacon cuando después de escuchada su condena expresó:

He sido el juez más justo que ha habido en Inglaterra en estos cincuenta años. Pero ésta ha sido la censura más justa pronunciada en el Parlamento en estos doscientos años. ${ }^{33}$

Es esta presunción la que fundamenta la prohibición de recibir regalos o aceptar invitaciones costosas impuesta a los funcionarios públicos de algunos países democráticos. En Alemania, a Lothar Späth, ex ministro presidente de Baden Württemberg, y a Max Streibl, ex ministro presidente de Baviera, el afán por gozar de turismo gratuito en el Caribe y aledaños les costó la carrera política, a pesar de que adujeron argumentos similares a los de la defensa baconiana.

15. Es obvio que la posibilidad de llevar a cabo la violación de una obligación será tanto mayor cuanto mayor sea el poder de discrecionalidad del decisor, puesto que ello aumenta las posibilidades de ganancias extraposicionales. Esto lo sabían ya los Incas:

Decían que dando licencia al juez para poder arbitrar, disminuían la majestad de la ley [...] y que era hacer venales los jueces y abrirles puerta para que, o por cohechos o por ruegos,

${ }^{32}$ Cfr. Hugh G. Dick, "Introduction", en Selected writings of Francis Bacon, 1955, Nueva York, Random House, p. XXVII.

${ }^{33}$ Cfr. ibidem, loc. cit. 


\section{ERNESTO GARZÓN VALDÉS}

pudiesen comprarles la justicia, de donde nacería grandísima confusión en la república, porque cada juez haría lo que quisiese $[\ldots]^{34}$

16. Hasta ahora, me he concentrado en los beneficios que obtienen quienes participan en el acto o actividad corrupto(a). Pero, conviene tomar en cuenta también hasta qué punto estos beneficios se obtienen a costa de terceros. Sostener sin más que toda corrupción afecta el bien común o el interés general es una aseveración propia de lo que he llamado "perspectiva moralizante", ya que si bien es cierto que todo acto o actividad corrupto(a) es disfuncional y antisistémico(a), también lo es que no todo sistema normativo relevante promueve el bien común.

Si no se quieren formular calificaciones apresuradas, tomando en cuenta las variables pago $(\mathrm{P})$ y obligación cumplida $(\mathrm{O})$ pueden construirse, por lo pronto, los siguientes 4 casos:

Caso 1) Es una situación de extorsión; se paga para que alguien cumpla su obligación; el daño es que ahora el servicio es más caro y quedan excluidos los que no pueden pagar la suma extorsionada.

Caso 2) Es una situación de soborno; se paga para que no se cumpla la obligación. También aquí resultan perjudicados quienes se beneficiarían del cumplimiento de la obligación.

Tanto en 1) como en 2) hay un daño intrasistémico. Pero, la evaluación última de este daño no depende del sistema normativo relevante sino del sistema normativo justificante o excusante. En efecto, lo que está aquí en juego es la legitimidad o ilegitimidad de los fines perseguidos por el sistema normativo relevante. Y ésta es una cuestión que no puede ser resuelta a nivel del sistema normativo relevante, a menos

${ }^{34}$ Cfr. Inca Garcilaso de la Vega, Comentarios Reales de los Incas, 1976, Caracas, Biblioteca Ayacucho, 2 vols., vol. 1, p. 87. 
que se quiera sostener que los sistemas normativos relevantes se justifican autorreferencialmente. En el caso de los sistemas políticos, esta posición conduce a la confusión entre legitimación y legitimidad. ${ }^{35}$

Joel Feinberg sugiere incluir el soborno en la categoría de los "crímenes impersonales", tales como la evasión de impuestos o el falso testimonio en un juicio. Los intereses aquí directamente afectados serían los "intereses gubernamentales", es decir, aquellos que se generan por la misma actividad de gobernar. Estos intereses deberían ser distinguidos de los "intereses públicos", es decir, aquéllos que son tan ampliamente compartidos que podría decirse que los posee la propia comunidad, tales como la paz pública, la salud o la defensa nacional. Es obvio que el daño a los intereses gubernamentales no siempre significa un daño a los intereses de la comunidad o de los individuos que no forman parte del gobierno. También en el caso de regímenes dotados de legitimidad podrían valer las siguientes consideraciones de Feinberg:

Un acto de envenenar el abastecimiento de agua afecta un interés de la comunidad y me perjudica directamente; el soborno de un funcionario público me afecta sólo indirecta y remotamente, pero me amenaza directamente con un daño en la medida en que pone en peligro el funcionamiento del sistema de gobierno en cuyo funcionamiento normal y eficaz estoy interesado. $^{36}$

Caso 3) No se paga y se cumple la obligación; no hay daño sistémico, pero justamente ello podrían afectarse intereses individuales legítimos. Puede pensarse aquí en el caso

${ }^{35}$ Con respecto a esta distinción, cfr. Ernesto Garzón Valdés, "Consenso, racionalidad y legitimidad" en, del mismo autor, Derecho, ética y política, 1993, Madrid, Centro de Estudios Constitucionales, p. 455-71.

${ }^{36} \mathrm{Cfr}$. Joel Feinberg, Harms to others. The moral limits of the criminal law, 1984, Nueva York/Oxford, Oxford University Press, p. 64. 


\section{ERNESTO GARZÓN VALDÉS}

del campo de concentración o de sistemas que establecen diferencias injustas entre sus ciudadanos, diferencias que sólo podrían ser superadas sobornando a los decisores competentes.

Caso 4) No se paga y la obligación no se cumple; desde el punto de vista del sistema normativo relevante, existe un daño frente al que puede reaccionar imponiendo sanciones o autorizando, quizás tácitamente, el otorgamiento de beneficios extraposicionales. Esta última sería, según no pocos autores, la situación en algunos países del llamado Tercer Mundo. ${ }^{37}$

17. Si se acepta lo hasta aquí expuesto, puede procederse ahora a reflexionar acerca de cuáles son los recursos que puede utilizar un sistema normativo para impedir o reducir la corrupción. Entre éstos, hay algunos que valen para todo sistema normativo relevante y otros que son aplicables a aquéllos que están moralmente justificados, es decir, en el caso de los sistemas políticos, que poseen legitimidad. Veamos los primeros. Son básicamente los cinco siguientes:

a) Eliminar la posibilidad de obtención de ganancias extraposicionales. Si es verdad que la discrecionalidad del decisor abre la vía del soborno, nada mejor entonces que sustituir las decisiones discrecionales por decisiones mecánicas.

Este fue el recurso de los Incas: sujetaron a los jueces a la aplicación incondicionado de prescripciones legales que establecían una pena única para cada tipo de delito. Es un recurso simple utilizado también por regímenes totalitarios. Pero no es necesario pensar en estos casos extremos. Cuando, por ejemplo, para el otorgamiento de órganos para transplantes se aplica el criterio del orden de precedencia de los solicitantes en igualdad de condiciones de necesidad, se recurre a un tipo de

${ }^{37}$ Cfr., por ejemplo, Thomas L. Carson, op. cit. 
decisión mecánica que ha demostrado ser eficiente para eliminar los casos de corrupción dentro del sistema sanitario. El "método de la cola" puede ser un recurso eficiente y moralmente no reprochable en ciertos contextos sistémicos.

b) Reducir la probabilidad de actos o actividades corruptos(as) estableciendo un sistema se sanciones severas para la violación de las obligaciones. Es el más común de los recursos y está presente en todos los sistemas normativos relevantes. El problema de las sanciones es que son recursos que podrían ser llamados "externos al agente", tanto al que corrompe como al que es corrompido $\mathrm{y}$

[...] si las únicas estrategias disponibles fueran las externas [...] no estaría justificado tener esperanzas de progreso moral. Tales fuerzas son típicamente reactivas y ganan sólo guerras defensivas. ${ }^{38}$

c) Asegurar a quienes son sujetos de obligaciones condiciones tales que el deseo de obtener beneficios extraposicionales se reduzca al máximo. Ésta es la estrategia que respalda la asignación de salarios significativos a quienes son decisores importantes dentro del sistema normativo relevante. Pero, aquí caben las consideraciones de Nani L. Ranken:

Los individuos que habitualmente toman decisiones importantes calculando sólo las consecuencias posibles de las acciones alternativas para su propio bien, también a largo plazo, están a menudo motivados por la prudencia y no confiamos en su capacidad para formular juicios mo-

${ }^{38}$ Cfr. Nani L. Ranken, "Morality in Business: disharmony and its consequences", en Journal of Applied Philosophy, 1987, vol. 4, n 1, p. 418 y 46. 


\section{ERNESTO GARZÓN VALDÉS}

rales o implementar decisiones morales si los sacrificios requeridos no han de ser resarcidos. ${ }^{39}$

Ya lo sabía Nicolás Maquiavelo:

[L]os deseos humanos son insaciables, pues la naturaleza humana desea y quiere todo [...] de aquí surge [...] una eterna insatisfacción $[\ldots]^{40}$

En este sentido, todo agente sujeto a obligaciones es corrompible y todo sistema normativo es potencialmente corrupto.

d) Procurar convencer a los decisores que no es verdad que la obtención de beneficios extraposicionales es la expresión de una actitud racional-prudencial sino que lo que vale la pena desde el punto de vista de la promoción de los propios intereses es justamente lo inverso, es decir, ser honesto. Para reforzar este recurso podría imponerse a todos los decisores la lectura de una versión popularizada del libro de David Gauthier Morals by Agreement, ${ }^{41}$ el intento más significativo de mostrar hasta qué punto ser honesto es el comportamiento racional por excelencia, simultáneamente, por ejemplo, el trabajo de Ruth Zimmerling, "La pregunta del tonto y la respuesta de Gauthier", con lo que el lector quedaría entonces convencido de las debilidades de los argumentos de Gauthier y se sentiría reafirmado en su interés por beneficios extraposicionales. ${ }^{42}$

e) Asegurar que los decisores adopten un punto de vista interno con respecto a las reglas básicas del sistema normativo relevante. Este es un recurso que apunta a las convicciones de los

${ }^{39}$ Cfr. Nani L. Ranken, op. cit., p. 44.

${ }^{40}$ Cfr. Nicolás Maquiavelo, Discorsi, 1977, Stuttgart, Kröner, p. 163.

${ }^{41}$ 1980, Oxford, Clarendon Press.

${ }^{42} \mathrm{Cfr}$. Ruth Zimmerling, "La pregunta del tonto y la respuesta de Gauthier", en Doxa 6, 1989, p. 49-76. 
decisores. Si el acto o la actividad corruptora es una expresión de deslealtad o de traición, contar con decisores leales es un buen recurso para evitar la corrupción. Ello es obvio, como también lo es que cuando se trata de adhesiones de convicción, los argumentos racionales suelen ser poco eficaces ante las murallas de la subjetividad individual. Esto también lo sabían los Incas y por ello reforzaban sus procesos mecánicos de decisión con una versión teocrática de la sociedad. Los regímenes totalitarios suelen recurrir a la ideología de un partido y en los sistemas deportivos se suele intentar imponer el credo del fair play, creando al mismo tiempo las circunstancias adecuadas para que pueda ser practicado. Como ejemplo de lo primero, podrían recordarse las observaciones de Stephen D. Morris con respecto a los casos de Cuba y Vietnam del Norte:

Aunque en estos casos el Estado es claramente dominante $\mathrm{y}$, a menudo, está difundido un nivel bajo de corrupción, la fuerza del componente anticorrupción de la ideología legitimante impide un mayor abuso del poder. ${ }^{43}$

Como ejemplo de lo segundo, puede pensarse en el caso del hockey libre en Canadá, en donde lo único que cuenta es el juego en sí como una competición fair-libre de beneficios externos:

Como en el hockey libre no hay beneficios extrínsecos que motiven la dominación, lo que cuenta es la propia actividad competitiva. [...] El triunfo no se convierte nunca en un beneficio o pérdida externos al juego. [...] la actividad competitiva se da en el plano de la 'competencia con uno mismo'; el adversario es un aliado que proporciona la oca-

${ }^{43}$ Stephen D. Morris, op. cit., p. 15. 
ERNESTO GARZÓN VALDÉS

sión necesaria para esta prueba; no es un enemigo en contra del acceso a apreciados beneficios externos al juego. ${ }^{44}$

18. Para un sistema democrático valen también estos recursos, con todos los inconvenientes indicados y algunas restricciones que dificultan aún más el remedio.

Así, por ejemplo, dado que todo sistema democrático está interesado en respetar la autonomía individual, justamente en el caso de los decisores, no puede admitir una reducción sensible de la discrecionalidad. Ella vale sólo para situaciones especiales, como puede ser la ya mencionada de adjudicación de órganos para transplantes. Tanto en el caso de los legisladores como en el de los jueces, el sistema democrático procura asegurarles un amplio margen de discrecionalidad. Basta pensar en la institución del mandato libre y el rechazo del mandato imperativo o coger cualquier Código Penal democrático y leer la parte especial y los límites máximos y mínimos de las penas que están autorizados a imponer los jueces. Los sistemas democráticos promueven vías de influencia en los decisores precisamente porque aspiran a que sean tenidos en cuenta los intereses de sus ciudadanos. Pero, no sólo deben tomarse en cuenta todos los intereses sino que ellos deben ser tenidos en cuenta equitativamente, es decir, debe procurarse la mayor igualdad posible de oportunidades de influencia. La dificultad empírica de controlar las violaciones del ejercicio legítimo de influencias es lo que justamente suele volver a las democracias mucho más vulnerables a la corrupción que los Estados totalitarios, una de cuyas características es precisamente la imposición de vallas al ingreso de influencias ajenas al aparato decisor del Estado.

${ }^{44}$ Cfr. J. McMurtry, op. cit. p. 207. Un caso diametralmente opuesto al de una competición libre fue el del partido de fútbol entre el Liverpool y el Newcastle al que se ha hecho referencia en la nota 13. La organización asiática que sobornó a Bruce Grobbelar habría ganado más de 15 millones de dólares en las apuestas de Singapur, Hong Kong y Malasia. Cfr. El País del 10.11.1995, p. 55. 
Esta cuestión está estrechamente vinculada con el tema de la corrupción de un sistema político democrático a través del poder del dinero. Dada la posibilidad de ejercer influencia en los decisores, promovida por el Propio sistema democrático, y la potencia económica de algunos intereses organizados, lo que al final probablemente resulta es, dicho con la plástica fórmula de Arthur S. Miller, un "gobierno del pueblo, por las corporaciones, para los ricos". ${ }^{45}$ Peter Graf Kielmansegg ha formulado lúcidas observaciones sobre esta problemática, que puede ser entendida como la pérdida de la soberanía interna del Estado, que se manifestaría en la instrumentalización de las instituciones del Estado, en el bloqueo de las mismas o en el ejercicio de un poder de conducción autónomo. Los Estados totalitarios pueden reaccionar ante estos desafíos eliminando las limitaciones a la libertad de acción de los decisores estatales y haciendo que la política dependa lo menos posible de la aprobación de los afectados, es decir, aumentando el poder de los decisores a costa del consentimiento de los destinatarios de sus decisiones. Pero, obviamente, ello no es posible en un Estado democrático:

Son características de los Estados constitucionales liberales dos condiciones contrarias: Debe aumentarse la capacidad de solución de los problemas (por parte del Estado) sin que por ello se desplacen básicamente los límites del campo de acción del Estado. Y: toda ampliación de la capacidad de solución de los problemas (por parte del Estado) aumenta la necesidad de aprobación. $^{46}$

Si, siguiendo a Kielmansegg, se establece una distinción entre aprobación general (la que puede darse, por ejemplo, en las elecciones) y

${ }^{45} \mathrm{Cfr}$. para esta referencia y las consideraciones siguientes, Peter Graf Kielmansegg, "Organisierte Interessen als 'Gegenregierungen'?", en Wilhelm Hennis, Peter Graf Kielmansegg y Ulrich Matz, Regierbarkeit, 1979, Stuttgart, Klett-Cotta, tomo II, p. 139-76, p. $147 \mathrm{~s}$.

${ }^{46}$ Ibidem, p. 174. 


\section{ERNESTO GARZÓN VALDÉS}

aprobación específica de los afectados directamente, puede también aceptarse la siguiente hipótesis:

Si se intenta aumentar la capacidad de solución de problemas del Estado sin ampliar sus márgenes de acción, la consecuencia es una creciente dependencia de la aprobación específica a costa de la dependencia de la aprobación generalizada. Dependencia de la aprobación específica significa dependencia de los intereses organizados. ${ }^{47}$

Teniendo esto en cuenta y dado que los intereses particulares organizados ejercen siempre una influencia apreciable en los decisores del Estado, un sistema democrático debería

f) procurar establecer una relación de cooperación con los intereses organizados, dentro del marco de lo que ha solido llamarse "corporativismo liberal". Esta cooperación presupone establecer relaciones equitativas de confianza y lealtad recíprocas entre el Estado y los intereses organizados.

Stephen D. Morris propone una vía en cierto modo similar cuando, al referirse a la situación óptima para evitar la corrupción en una democracia, señala la necesidad de establecer un equilibrio estructural entre las organizaciones sociales y el Estado:

Cuando el Estado y las organizaciones sociales protegen y promueven sus propios intereses e intentan controlar las inclinaciones personales, el punto muerto producido por las presiones cruzadas resulta en una burocracia no politizada y profesional que sigue (a veces religiosamente) las reglas articuladas de la institución política y el espíritu del derecho escrito; funcionarios públicos y burócratas res-

${ }^{47}$ Ibidem, loc. cit. 


\section{EL CONCEPTO DE CORRUPCIÓN}

ponsables; y la difusión de los valores modernos antitéticos a la corrupción en un nivel moral y ético. ${ }^{48}$

El equilibro estructural de las fuerzas de las organizaciones estatales y de las organizaciones sociales determinan los límites hasta donde los miembros de una organización pueden promover exclusivamente sus propios intereses personales. La corrupción se produciría por un desequilibrio estructural esencial entre la habilidad y capacidad del Estado y de las organizaciones sociales para influenciar el comportamiento político: si predominan los intereses de las organizaciones sociales, existe una tendencia fuerte al soborno; si las organizaciones estatales no tienen el contrapeso de las sociales, aquéllas tenderán al abuso del poder y a la extorsión:

Dada la capacidad superior de las organizaciones estatales para influir en el comportamiento y la debilidad concomitante de las organizaciones sociales para reducir el poder del Estado, los funcionarios públicos pueden explotar plenamente su posición superior, a veces exclusivamente para su beneficio personal. ${ }^{49}$

Podría, desde luego, aducirse que la propuesta del "corporativismo liberal" y, sobre todo, la del equilibrio estructural, son demasiado vagas y no hacen referencia a la calidad de sus influencias en el sistema democrático, calidad que depende, por cierto, del tipo de grupos de intereses de que se trate. Ésta es la opinión de Amitai Etzioni con su distinción entre grupos de intereses especiales, organizaciones de representación del electorado y grupos de intereses públicos. ${ }^{50}$ En este sentido, la in-

48

${ }^{49}$ Ibidem, loc. cit.

${ }^{50}$ Cfr. Amitai Etzioni, op. cit., p. 201 y s. 


\section{ERNESTO GARZÓN VALDÉS}

fluencia de los grupos de intereses especiales suele carecer de las posibles consecuencias positivas que se atribuyen a los dos otros tipos. Ello aconsejaría una mayor cautela con respecto a la influencia de los grupos de intereses y reduciría el alcance del "corporativismo liberal" o del "equilibrio estructural".

g) Asegurar la vigencia del principio o sólo de las decisiones sino del procedimiento por el que se llega a ellas. Si se quiere mantener la discrecionalidad de los decisores, un buen método para impedir sus desviaciones corruptas puede ser asegurar una mayor transparencia en la gestación de las mismas. Pero, el principio de publicidad sólo garantiza la accesibilidad a la gestación de las decisiones y no el ejercicio efectivo del derecho de acceso. Cuán reducida puede ser la práctica de este derecho en las democracias es un tema sobre el que no habré de insistir aquí. ${ }^{51}$

h) Reducir el ámbito del poder decisorio del Estado y aumentar el de las decisiones directas de los ciudadanos por lo que respecta al nombramiento de los funcionarios. De esta manera podría evitarse la prevalencia de intereses puramente partidistas en la designación de miembros del Poder Ejecutivo y Judicial. Es la propuesta de Hans Herbert von Arnim. ${ }^{52}$

i) Promover la adquisición de bienes para uso estatal en las condiciones generales del mercado. El Estado se convertiría en este caso en un comprador más. Es la propuesta de Susan RoseAckerman:

[...] cuando el gobierno adquiere un bien que se vende también en el mercado privado, los incentivos para el soborno son sustancialmente menores que aquéllos que se dan cuando el gobierno es el único comprador. [...] cuan-

${ }^{51}$ Para un tratamiento detallado de este problema, cfr. Ernesto Garzón Valdés, "Acerca de los conceptos de publicidad, opinión pública y opinión de la mayoría y sus relaciones recíprocas", en Doxa 14, 1993, p. 77-95.

${ }^{52}$ Cfr. Hans Herbert von Arnim, op. cit., p. $150 \mathrm{~s}$. 
do los bienes tienen que ser ordenados especialmente para el uso gubernamental, habría que diseñar políticas para reducir la vaguedad en las instrucciones de adquisición que se imparten a los funcionarios, reduciendo así los costos de una vigilancia eficaz y aumentando la probabilidad de detectar malversaciones graves. ${ }^{53}$

La lista de estas medidas podría, por cierto, extenderse aún más. ${ }^{54}$ Pero todas ellas serán posiblemente ineficaces si no están basadas en una práctica efectiva de la adhesión interna al sistema democrático por parte de sus decisores. Es ella que asegura aquel cumplimiento de las obligaciones "a veces religiosamente" para usar la expresión de Stephen D. Morris.

Es interesante en este sentido señalar que Amitai Etzioni, al concluir su análisis de los grupos de intereses "buenos" y "malos" en el sistema democrático afirme:

Lo mejor sería estimular las fuerzas que sostienen la comunidad y hacerlas menos vulnerables a las presiones de los grupos de intereses, fuerzas que incluyen un cambio de actitud (o de corazón) desde un excesivo egoísmo a mayores comprometimientos cívicos y revitalización de las instituciones. ${ }^{55}$

${ }^{53} \mathrm{Cfr}$. Susan Rose-Ackerman, "The economics of corruption", en Journal of Public Economics 4, 1975, p. 187-203 y 202.

${ }^{54}$ Existen verdaderos catálogos de medidas contra la corrupción. Al respecto pueden consultarse, entre otros, Robert Klitgaard, op. cit.; Luis Moreno Ocampo, En defensa propia. Cómo salir de la corrupción, 1993, Buenos Aires, Sudamericana; Rogelio Pérez Perdomo y Ruth Capriles, Corrupción y control. Una perspectiva comparada, 1991, Caracas, IESA; Carlos S. Nino, Un país al margen de la ley, 1992, Buenos Aires, Emecé.

${ }^{55}$ Cfr. Amitai Etzioni, op. cit., p. 218. 
ERNESTO GARZÓN VALDÉS

19. He sostenido más arriba que los sistemas normativos relevantes carecen de la capacidad de autolegitimarse. La calidad de un sistema normativo le es otorgada por otro sistema normativo jerárquicamente superior: el "sistema normativo justificante". Esta relación de jerarquías puede, en algunos casos, ser más o menos arbitraria o circunstancial. Así, por ejemplo, podría pretenderse justificar la corrupción deportiva recurriendo a un sistema político al que se le confiere una jerarquía superior. Así al menos lo pensaron probablemente el dictador argentino Jorge Rafael Videla y sus cómplices cuando -según se dijo en su hora- "compraron" el Campeonato mundial de fútbol de 1978. Si la crónica es verdadera, el soborno a los peruanos habría estado justificado por "razones políticas superiores", que en la versión videlista consistían en la defensa del mundo occidental y cristiano. Pero, esta cadena de sistemas normativos justificantes termina finalmente en un sistema normativo justificante supremo: el de la moral crítica o ética. Es innecesario abundar en argumentos para demostrar la insuficiencia moral de la justificación política del dictador argentino. Hasta qué punto haya habido casos en la historia en los cuales la corrupción significó un progreso moral es algo cuya consideración puede ser aquí

208 dejada de lado; quizás baste recordar que en el caso de Inglaterra

los ajustes de 1660 y 1688 inauguraron la Edad de la Razón y sustituyeron con un sistema de patronato, soborno y corrupción el método anterior del derramamiento de sangre. ${ }^{56}$

Entre los sistemas políticos normativos relevantes, hay uno del que cabalmente puede predicarse legitimidad, en el sentido de que sus principios y reglas satisfacen las exigencias de una moral crítica o ética: el de la democracia representativa institucionalizada en el Estado social

${ }^{56}$ Cfr. Jon Elster, op. cit., p. 265. Cfr. también Robin Theobald, Corruption, Development and Underdevelopment, 1990, Durham, Duke University Press, p. $124 \mathrm{~s}$. 
de derecho. Porque ello es así, la violación de las obligaciones por parte de sus decisores (y aquí cabe incluir no sólo a los funcionarios sino también a los ciudadanos en el acto electoral $)^{57}$ es siempre no sólo intrasistémicamente disfuncional sino también inmoral. Ello confiere a la corrupción en la democracia un carácter que no está necesariamente presente en los demás sistemas políticos. Aquí no cabe la actitud del revolucionario, y la deslealtad de los decisores se vuelve inexcusable.

20. El tema de la corrupción política es un "tema de moda". La abundancia de libros y escritos periodísticos, de programas de TV destinadas a esta cuestión es realmente inmensa. Pero su importancia no radica tanto en la magnitud del fenómeno "corrupción" cuanto en su carácter de síntoma de males más graves y profundos.

Si la corrupción política fuera únicamente una vía de enriquecimiento de camarillas, si afectase directamente sólo intereses gubernamentales, como afirma Feinberg, de competidores en ámbitos más o menos delimitados, o si se redujese a elevar el costo de servicios del Estado, entonces, a pesar de que no habría dudas acerca de su relevancia delictiva, podría pensarse que una sociedad democrática podría convivir con este tipo de delito, tal como lo hace con otros manifiestamente graves. En todo caso, podría aducirse, mucho más grave que el enriquecimiento ilegítimo es el homicidio, delito no poco frecuente también en las sociedades democráticas.

Ello es verdad. Pero también lo es que la corrupción se vuelve posible y prospera cuando los decisores abandonan su punto de vista interno y actúan deslealmente con respecto al sistema normativo. La corrupción es una forma de "explotación segmentaria de la descon-

${ }^{57}$ John Rawls, op. cit., p. 113 s., niega la existencia de obligaciones políticas en sentido estricto en el caso de los ciudadanos. Creo más acertada la posición de Dolf Sternberger, Herrschaft. und Vereinbarung, 1986, Francfort, Suhrkamp, p. 122 s., cuando fundamenta la existencia de obligaciones ciudadanas (en el sentido de deberes posicionales) en el acto electoral. 


\section{ERNESTO GARZÓN VALDÉS}

fianza" ${ }^{58}$ cuyas probabilidades de éxito están directamente relacionadas no sólo con la existencia de beneficios extraposicionales sino también con la pérdida de la confianza en formas de cooperación y de distribución de cargas y beneficios sobre la base del respeto de la autonomía individual, de la igualdad de oportunidades y de la confianza recíproca, propuesta por la democracia.

El problema de la lealtad democrática, de la eliminación de la posibilidad de gorrones y de parásitos, es posiblemente una de las cuestiones centrales de la democracia actual. No es casual que una buena parte de la discusión entre liberales y comunitaristas gire alrededor del tema de la lealtad democrática. Tampoco lo es el hecho de que la mayor parte de los recursos propuestos para combatir la corrupción están directamente relacionados con el reforzamiento de aspectos básicos del sistema democrático, tales como la vigencia plena del principio de publicidad, la discrecionalidad de las decisiones, ${ }^{59}$ la igualdad de consideración de los intereses de los ciudadanos o los procedimientos de elección y designación de los decisores oficiales.

Los actos y actividades corruptos(as) son sólo la punta de un iceberg que indica la existencia de un problema mucho más profundo: el

210 de la tendencia a sustituir el ideal de la cooperación democrática por formas de competencia y de imposición de influencias que contradicen radicalmente el ideal democrático. La alarmante difusión de la corrupción se debe no sólo al atractivo cada vez mayor de los beneficios extraposicionales sino también al hecho de que la realización efectiva de la democracia representativa tropieza con obstáculos tan serios que

${ }^{58}$ Cfr. Diego Gambetta, "Mafia: the Price of Distrust", en D. Gambetta (ed.), Trust. Making and Breaking Cooperative Relations, 1988, Nueva York, Basil Blackwell, p. 158-75 y 166. Gambetta utiliza esta expresión para el caso de la mafia pero pienso que vale también para la corrupción en las sociedades democráticas.

${ }^{59}$ Con respecto a las relaciones entre discrecionalidad y corrupción $\mathrm{cfr}$., por ejemplo, Anthony Downs, Inside Bureaucracy, 1967, Boston, Little, Brown and Company, p. 61-73. 


\section{EL CONCEPTO DE CORRUPCIÓN}

cada vez es también mayor el número de quienes atribuyen carácter utópico al proyecto democrático de la modernidad. Por ello, la recuperación de la fe democrática y la puesta en práctica de propuestas que hagan posible la viabilidad de una convivencia en condiciones de equidad es el medio más seguro para evitar los efectos disolventes de la corrupción en una sociedad democrática. 